\title{
Determining the burden of fungal infections in Zimbabwe
}

\author{
Lorraine T. Pfavayi $i^{1,2,3 凶}$, David W. Denning ${ }^{4}$, Stephen Baker ${ }^{5,6}$, Elopy N. Sibanda ${ }^{7,8,9}$ \& \\ Francisca Mutapi ${ }^{2,3}$
}

Zimbabwe currently faces several healthcare challenges, most notably HIV and associated infections including tuberculosis (TB), malaria and recently outbreaks of cholera, typhoid fever and COVID-19. Fungal infections, which are also a major public health threat, receive considerably less attention. Consequently, there is dearth of data regarding the burden of fungal diseases in the country. We estimated the burden of fungal diseases in Zimbabwe based on published literature and 'at-risk' populations (HIV/AIDS patients, survivors of pulmonary TB, cancer, chronic obstructive pulmonary disease, asthma and patients receiving critical care) using previously described methods. Where there was no data for Zimbabwe, regional, or international data was used. Our study revealed that approximately $14.9 \%$ of Zimbabweans suffer from fungal infections annually, with $80 \%$ having tinea capitis. The annual incidence of cryptococcal meningitis and Pneumocystis jirovecii pneumonia in HIV/AIDS were estimated at 41/100,000 and 63/100,000, respectively. The estimated prevalence of recurrent vulvovaginal candidiasis (RVVC) was 2,739/100,000. The estimated burden of fungal diseases in Zimbabwe is high in comparison to other African countries, highlighting the urgent need for increased awareness and surveillance to improve diagnosis and management.

Africa has an estimated population of 1.3 billion people and accounts for about $75 \%$ of all the 38 million human immunodeficiency virus (HIV)-infected people in the world. Notably, approximately $50 \%$ of all fungal-related deaths due to HIV infections are thought to occur in Africa; however accurate data are lacking ${ }^{1,2}$. Data generated by the Global Action Funds for Fungal Infections (GAFFI), suggests an estimated 47.6 million Africans suffer from fungal diseases, of which 1.7 million suffer annually from a serious fungal infection ${ }^{3}$. However, these estimates are based on data from only a few African countries, and most likely underestimates the true prevalence.

Fungal diseases are life-threatening and are responsible for a largely silent epidemic, often hidden killers causing substantial morbidity and mortality in susceptible individuals ${ }^{4}$. Patients with fungal infections occur across a huge spectrum of medical conditions often as co-infections or opportunistic infections ${ }^{5}$ and are thus treated as separate entities, hindering progress in diagnosis and management of these patients ${ }^{6}$. Only skin, hair, nails and mucosal infections can be clinically diagnosed (with much imprecision) without specific laboratory testing or medical assessment (radiology, mycology, histopathology) with expensive technologies requiring trained personnel. On the other hand, most life-threatening infections require the referred methods to be diagnosed, which is often out of the reach of patients in poor resource settings.

Nonetheless, substantial progress is being made to prevent and manage some of these fungal diseases. Mycetoma and chromoblastomycosis have been included in the World Health Organisation (WHO) list of neglected tropical diseases ${ }^{7,8}$ and new guidelines for the prevention and management of cryptococcal meningitis were recently issued ${ }^{3}$.

Fungal infections such as histoplasmosis, mycetoma, chromoblastomycosis, sporotrichosis, cryptococcal meningitis and tinea capitis ${ }^{9-13}$ have been reported in Zimbabwe, albeit in few and dated reports. Therefore, there

\footnotetext{
${ }^{1}$ Nuffield Department of Medicine, Centre for Tropical Medicine and Global Health, University of Oxford, Old Road Campus, Roosevelt Drive, Oxford OX3 7LG, UK. ${ }^{2}$ Institute of Immunology and Infection Research, University of Edinburgh, Ashworth Laboratories, King's Buildings, Charlotte Auerbach Road, Edinburgh EH9 3FL, UK. ${ }^{3} \mathrm{NIHR}$ Global Health Research Unit Tackling Infections To Benefit Africa (TIBA), University of Edinburgh, Ashworth Laboratories, King's Buildings, Edinburgh, UK. "Manchester Fungal Infection Group, The University of Manchester and Manchester Academic Health Science Centre, Manchester, UK. ${ }^{5}$ University of Cambridge School of Clinical Medicine, Cambridge Biomedical Campus, Cambridge CB2 OAW, UK. ${ }^{6}$ Department of Medicine, University of Cambridge School of Clinical Medicine, Cambridge Biomedical Campus, Cambridge CB2 2OQ, UK. ${ }^{7}$ Asthma Allergy and Immunology Clinic, Twin Palms Medical Centre, Harare, Zimbabwe. ${ }^{8}$ TIBA Zimbabwe, NIHR Global Health Research Unit Tackling Infections To Benefit Africa (TIBA), University of Edinburgh, Edinburgh, UK. ${ }^{9}$ Department of Pathology, National University of Science and Technology (NUST) Medical School, Bulawayo, Zimbabwe. ${ }^{\circledR}$ email: lorraine.pfavayi@kellogg.ox.ac.uk
} 


\begin{tabular}{|c|c|c|c|c|c|c|c|c|}
\hline \multicolumn{9}{|c|}{ Number of Infections per underlying disorder per year } \\
\hline Infection & None & HIV/AIDS & $\begin{array}{l}\text { Respiratory } \\
\text { disease }\end{array}$ & Cancer & $\begin{array}{l}\text { Critical } \\
\text { care + surgery }\end{array}$ & Totals & Burden & Rate/100,000 \\
\hline $\begin{array}{l}\text { Cryptococcal } \\
\text { meningitis }\end{array}$ & & 6086 & & & & 6086 & I & 41 \\
\hline \begin{tabular}{|l}
$\begin{array}{l}\text { Pneumocystis } \\
\text { pneumonia }\end{array}$ \\
\end{tabular} & & 9429 & & & & 9429 & I & 63 \\
\hline $\begin{array}{l}\begin{array}{l}\text { Invasive aspergil- } \\
\text { losis }\end{array} \\
\end{array}$ & & 800 & 19 & 46 & 1582 & 2448 & I & 16 \\
\hline CPA & & & 6182 & & & 6182 & $\mathrm{P}$ & 42 \\
\hline ABPA & & & 14,892 & & & 14,892 & $\mathrm{P}$ & 100 \\
\hline SAFS & & & 19,657 & & & 19,657 & $\mathrm{P}$ & 132 \\
\hline Candidaemia & & & & 520 & 223 & 743 & I & 5.0 \\
\hline \begin{tabular}{|l} 
Candida perito- \\
nitis \\
\end{tabular} & & & & & 111 & 111 & I & 0.8 \\
\hline Oral candidiasis & & 77,143 & & & & 77,143 & I & 519 \\
\hline $\begin{array}{l}\text { Oesophageal } \\
\text { candidiasis }\end{array}$ & & 63,571 & & & & 63,571 & I & 427 \\
\hline $\operatorname{RVVC}(\geq 4 \mathrm{x} /$ year $)$ & 203,585 & & & & & 203,585 & $\mathrm{P}$ & $2739^{a}$ \\
\hline Mucormycosis & & & & 30 & & 30 & I & 0.2 \\
\hline Histoplasmosis & & 57 & & & & 57 & I & 0.4 \\
\hline \begin{tabular}{|l} 
Fungal keratitis \\
\end{tabular} & 2081 & & & & & 2081 & I & 14 \\
\hline Tinea capitis & $1,806,700$ & & & & & $1,806,700$ & $\mathrm{P}$ & 12,156 \\
\hline \begin{tabular}{|l|}
$\begin{array}{l}\text { Total burden } \\
\text { estimated }\end{array}$ \\
\end{tabular} & $2,012,366$ & 157,086 & 40,750 & 596 & 1916 & $2,212,715$ & & $16,255.4$ \\
\hline
\end{tabular}

Table 1. Estimated burden of fungal diseases in Zimbabwe. I Incidence; $P$ Prevalence; $A B P A$ Allergic bronchopulmonary aspergillosis; SAFS Severe asthma with fungal sensitisation; CPA Chronic pulmonary aspergillosis; $R V V C$ Recurrent Vulvovaginal Candidiasis ${ }^{a}$ Rate among all females.

is need to update the information on the burden of these infections in Zimbabwe if they are to be prioritised for health intervention.

In the last three decades Zimbabwe's health system has faced considerable issues ${ }^{14}$, most notably the demand for providing healthcare services for the control of HIV and associated tuberculosis (TB) as well as for other endemic infections such as malaria and schistosomiasis. The recent cholera ${ }^{15}$ and typhoid fever ${ }^{16}$ outbreaks further exacerbated Zimbabwe's health challenges. The impact of the current severe acute respiratory syndrome coronavirus (SARS-CoV-2) pandemic ${ }^{17}$ on the health system has yet to be fully realised. Thus, given the current health prioritisations in the context of limited resources, controlling fungal infections is currently not a national priority $^{6}$. This may only change with the quantification of the burden of these diseases and their impact on human health in Zimbabwean population.

Thus, in this study, we sought to provide estimates of the burden of fungal infections by using local published data; for those diseases with no existing local data, we used data from neighbouring countries, or international sources.

\section{Results}

Using previously described methods, we were able to estimate the occurrence of 2,212,715 cases of fungal infections each year in Zimbabwe (Table 1). The rate of each fungal disease per 100,000 people in Zimbabwe is also represented in Fig. 1.

HIV-related fungal infections. Cryptococcus neoformans complex, Pneumocystis jirovecii (previously Pneumocystis carinii) and oropharyngeal candidiasis are the fungal diseases most commonly associated with AIDS. According to the UNAIDS 2019 report, 1.4 million Zimbabweans were living with HIV, 85\% were on ART and 42,857 new AIDS cases at risk of opportunistic fungal infections ${ }^{18}$. C. neoformans complex is the most common cause of meningitis globally and is a leading cause of mortality among HIV-infected adults ${ }^{11,19,20}$ in these patients. We estimated 6,086 cases $(40 / 100,000)$ of cryptococcal meningitis. PCP is a major cause of infection in those with HIV/AIDS, and unfortunately, most of these patients are undiagnosed or diagnosed late, particularly in resource-limited settings ${ }^{21,22}$. In Zimbabwe, the largest reported series was 8 (22\%) cases of PCP in 1989 of HIV-infected individuals with respiratory symptoms ${ }^{23}$. Assuming $11 \%$ of newly diagnosed HIV/AIDS adults ${ }^{24}$, develop PCP over 2 years, we estimated 9429 cases $(63 / 100,000)$ of PCP. PCP may be proportionately more common in children with HIV and was likely a significant contributor to the 3000 children who died of AIDS in $2019^{18}$, but we did not estimate this separately due to the absence of data. We estimated oral candidiasis to affect 77,143 individuals and oesophageal candidiasis 63,571 people living with HIV (PLHIV).

Invasive aspergillosis (IA) and mucormycosis. We estimated a total of 2448 cases of IA annually $(16 / 100,000)$ including 45 cases in haematological malignancy, 19 cases among those with lung cancer, 800 


\section{Annual incidence and prevalence of fungal diseases in zimbabwe}
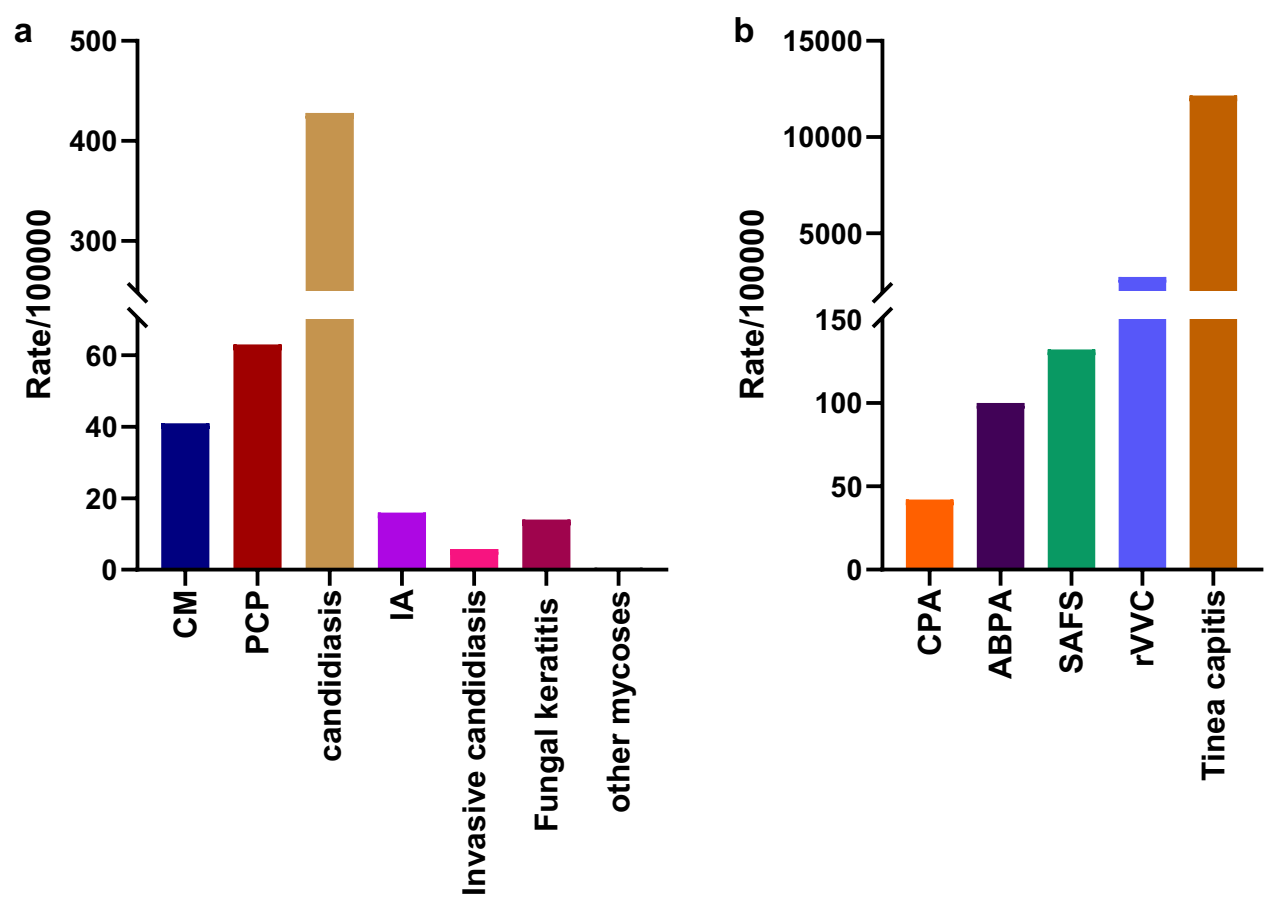

Fungal disease

Figure 1. Annual incidence and prevalence of fungal infections in Zimbabwe. Bar charts representing the burden of fungal diseases per 100,000 people (a) incidence and (b) prevalence for each fungal disease with data available. CM, Cryptococcal meningitis; PCP, Pneumocystis pneumonia; candidiasis (oesophageal candidiasis) ; Invasive candidiasis (candidaemia and Candida peritonitis); IA, Invasive aspergillosis; other mycoses (histoplasmosis and mucormycosis); CPA, Chronic pulmonary aspergillosis; ABPA, Allergic bronchopulmonary aspergillosis; SAFS, Severe asthma with fungal sensitisation; rVVC, recurrent vulvovaginal candidiasis.

cases among people who died HIV/AIDS and 1582 cases among persons admitted to hospital with COPD. The recognized association with transplantation procedures could not be estimated since these procedures were not undertaken in Zimbabwe during the relevant period. For mucormycosis we conservatively estimated only 30 cases $^{25}$.

Histoplasmosis. Histoplasmosis is poorly described in Zimbabwe with limited epidemiological data. However, a study by Oladele et al. ${ }^{26}$ reports that Histoplasmosis capsulatum var capsulatum (HCC) and Histoplasmosis capsulatum var duboisii (HCD) coexist in Zimbabwe. We estimate 57 cases of histoplasmosis per year. This estimate excluded non-disseminated forms of histoplasmosis.

Non-HIV-related fungal disease burden. Chronic pulmonary aspergillosis (CPA) is a complication of pulmonary TB that is often diagnosed late and may mimic pulmonary TB. It also affects patients with other pulmonary disorders, notably COPD, after pneumothorax and occasionally those with ABPA and asthma ${ }^{27}$. We estimated 6840 of CPA cases per year. Fungal allergy exacerbates asthma, especially in adults. The prevalence of asthma in adults in Zimbabwe was estimated to be 6.9\% using data from Democratic Republic of the Congo ${ }^{28}$. We estimated 14,892 and 19,657 cases per year of ABPA and SAFS respectively. There may be some duplication between these entities as many ABPA patients have severe asthma. Therefore, the true 'fungal asthma' prevalence may be $75 \%$ of their total. Cystic fibrosis has not reported from Zimbabwe.

Candidaemia and Candida peritonitis were estimated to affect 743 and 111 patients, respectively. We did not estimate Candida peritonitis complicating chronic ambulatory peritoneal dialysis.

RVVC is defined as four or more episodes of vulvovaginal candidiasis per year ${ }^{29}$. We estimated 203,585 RVVC to occur among adult women in the general healthy female population in their fertile years, which may be conservative. Hormone replacement therapy can precipitate $\mathrm{RVVC}^{30}$, but we did not estimate this.

Fungal keratitis often occurs following ocular trauma from vegetable material ${ }^{31,32}$ and male agricultural workers are at a greater risk ${ }^{33}$. It often leads to blindness and a recent global estimate found a culture and microscopy positive annual incidence of 14/100,000, which translates into approximately 2080 cases in Zimbabwe. However, assuming that culture and microscopy negative cases are usually cases of fungal keratitis ${ }^{34}$ in high incidence areas, 

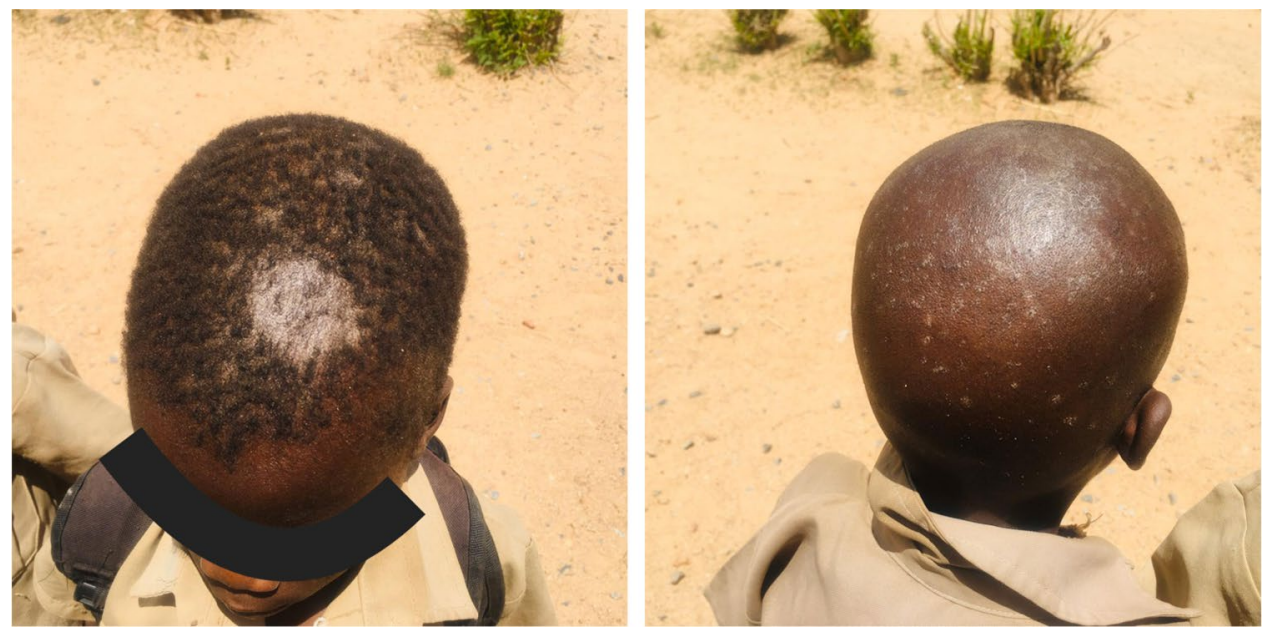

Figure 2. Tinea capitis infection in two young boys from rural Zimbabwe.

this number rises to approximately 2930 cases. Most of the infected eyes will go blind and some will perforate and require removal ${ }^{34}$.

Cutaneous fungal infections are very common in southern Africa, but here we focus only on tinea capitis, given its transmissibility, scarring potential and occasional complications of kerion ${ }^{35}$. We estimated 1,806,700 schoolchildren suffering from tinea capitis. The two most frequent dermatophyte species isolated from tinea cases in Zimbabwean children were Trichophyton violaceum and Microsporum audouinii ${ }^{9}$. These species have been shown to be the most frequent dermatophyte species involved in tinea capitis among children in southern Africa $^{36-39}$. This observation is in accordance with a recent systematic review estimating the burden of tinea capitis among children in Africa ${ }^{40}$. Figure 2 shows tinea capitis infection in two young school boys from rural Zimbabwe.

There were 14 chromoblastomycosis, 3 sporotrichosis and 5 mycetoma cases as reported by Ross and Gelfand in a 10-year survey of histological material ${ }^{12,13}$. Only four cases of blastomycosis were reported in $1991^{41}$, however some more recent isolates such as Blastomyces gilchristii have been described ${ }^{42,43}$. Given that these older estimates are the only available data in Zimbabwe, we cannot use them for a reliable estimate of the current burden. The reports however show that these conditions occur in this population and may be underdiagnosed and under reported.

\section{Discussion}

A diverse range of fungal infections commonly occurs in Zimbabwe. Frequent HIV and TB co-infections contribute to a higher prevalence of some fungal diseases. Each of these conditions on its own or in combination can predispose individuals to fungal diseases ${ }^{44}$. To date, the burden of fungal infections in Zimbabwe has not been documented. Therefore, we conducted this study to estimate the burden of fungal infections/diseases in the country. Our study indicated that over 2 million people [2,212,715 (14.9\%)] suffer from fungal disease annually, a higher number than most African countries. This figure is comparable to that of Senegal ${ }^{45}$ and Nigeria $^{46}$ with tinea capitis being the most predominant fungal infection.

In Zimbabwe, we found that, following tinea capitis, the most frequent serious fungal diseases were recurrent vulvovaginal candidiasis, oral and oesophageal candidiasis. Vulvovaginal candidiasis (VVC) is a common gynaecological problem occurring among women globally, most commonly caused by Candida albicans ${ }^{47,48}$. In previous studies carried out in Zimbabwe among women presenting with symptomatic vaginal discharge, VVC prevalence rates ranged between 25 and 40\% ${ }^{49,50}$ and we have estimated that 203,585 Zimbabwean women suffer from recurrent episodes. While recurrent vulvovaginal candidiasis (RVVC) is not life threatening, it is a significantly more severe clinical form than VVC. This is because of the recurrence of symptoms defined as four or more episodes per year ${ }^{29,51}$ and it is a major health problem for sexually active women. RVVC affects quality of life and is associated with anxiety, depression and a loss of productivity ${ }^{52-54}$. Our estimates, make the burden of RVVC in Zimbabwe the fifth highest among the Southern African Development Community (SADC) countries with available estimated burdens ${ }^{4,55-57}$ and some data indicate that the prevalence of RVCC may be higher in Africa than other continents ${ }^{54,58,59}$. Genetic factors have been suggested to be related to the susceptibility of Black/ African women to RVCC. However, comprehensive assessment of the role of genetics in RVCC is still lacking. Likewise, host-related and behavioural factors could also have a role to play ${ }^{51,60,61}$.

Oral and oesophageal candidiasis occurs commonly in AIDS patients or those with other immunosuppressive conditions. Oral candidiasis is one of the most common fungal opportunistic infections in immunocompromised individuals ${ }^{62,63}$ and was found to be the most common opportunistic infection in Nigeria ${ }^{64}$ and Uganda before the initiation of highly active antiretroviral therapy (HAART) ${ }^{65}$. Fluconazole is the drug of choice in the treatment of oral candidiasis ${ }^{62}$ because of its bioavailability and efficacy compared with other antifungal drugs ${ }^{66,67}$. However, an increase in resistance of Candida species to fluconazole has been reported in some parts of Africa ${ }^{68-71}$ and this is important to note because of the implications for morbidity and mortality rates ${ }^{71,72}$. 
Cryptococcal meningitis is the leading cause of meningitis in sub-Saharan Africa ${ }^{44,73}$. Recent studies have shown that an increasing proportion of patients with cryptococcosis are ART-experienced ${ }^{74,75}$. In Uganda $3 \%$ of

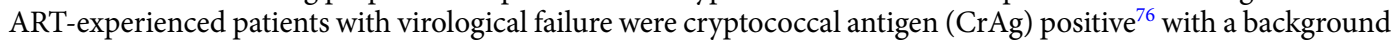
rate of 5-10\% cryptococcal meningitis. Consequently, to estimate the incidence of cryptococcal meningitis in Zimbabwe we doubled our at-risk population (ART naïve), being cognisant of the fact that virological failure does not always translate to immunodeficiency. We estimated the occurrence of 6086 cases of cryptococcal meningitis per year. We estimated 9429 cases of PCP in HIV/AIDS patients only. Although, PCP is common in children ${ }^{77-79}$ and also occurs in non-HIV infected patients we did not include these in our estimates due to paucity of data.

The prevalence of CPA was estimated at 42/100,000, which was relatively high compared to other African countries $^{55-57}$. South Africa had the highest prevalence, at 176/100,000 ${ }^{44}$. The high number in Zimbabwe could reflect the relatively high burden of tuberculosis ${ }^{80}$ and further studies are required to validate this. The diagnosis requires a combination of imaging and Aspergillus IgG antibody testing recently recognised as an Essential Diagnostic by $\mathrm{WHO}^{81}$, however these are not routinely done in Zimbabwe. Notably a fifth (19\%) of CPA patients who were TB smear negative and GeneXpert negative in Nigeria were incorrectly diagnosed as having pulmonary $\mathrm{TB}^{82}$ with consequent inappropriate treatment.

Asthma is a significant public health problem in Zimbabwe and is often poorly controlled ${ }^{83}$. Here we estimated that 595,677 adults have asthma. In Zimbabwe fungal sensitisation studies have not been conducted, nonetheless we were able to estimate the burden for ABPA and SAFS, which are collectively known as 'fungal asthma'. Fungal asthma differs from allergic asthma. Although the bronchoconstriction can be alleviated by the bronchodilators and inhaled glucocorticosteroids used in the management of asthma, fungal diseases requires the administration of antifungal agents such as oral itraconazole ${ }^{84-87}$ and voriconazole, which can only be prescribed if an accurate diagnosis has been made. These antifungal agents act by reducing the fungal load, thus minimizing the stimulus for the ongoing inflammatory activity ${ }^{88}$. If inadequately managed fungal asthma can lead to significant complications such as long term steroid toxicity, bronchiectasis and $\mathrm{CPA}^{89}$.

A review on the role of antifungals in the management of patients with severe asthma has recently been published ${ }^{87}$. The paper highlights significant studies that confirm lower toxicity of treatment with azoles, particularly itraconazole for ABPA and provide recommendations for the use of antifungal agents in patients with severe asthma, airways fungal infection and fungal colonisation ${ }^{87}$.

Dermatophyte infections, especially tinea capitis, are common among children all over Africa, particularly in areas with poor socioeconomic and sanitary conditions ${ }^{90-92}$. They are a public health problem due to their contagious nature ${ }^{55}$. Prevalence rates range from $10 \%$ to more than $70 \%$ in different regions of Africa ${ }^{9,40,93,94}$. The estimate of tinea capitis in this study was based on Zimbabwean data from $1990^{9}$. However, there may have been changes over time and these figures may not be a true presentation of the current situation in the country. Nonetheless, it remains a common clinical problem.

Mycetoma is a neglected tropical disease caused by fungi or bacteria and mainly affects the skin as well as the underlying tissues ${ }^{95}$. The morbidity due to mycetoma is high ${ }^{96}$ and there are currently no control programmes except in Sudan where it is highly endemic $\mathrm{c}^{7,8,97}$. Cases of mycetoma have been reported in many African countries $^{45,98-103}$ including Zimbabwe ${ }^{12}$. Cases of chromoblastomycosis, sporotrichosis and blastomycosis have also been reported in Zimbabwe. However, to date there are no reports of disseminated Emergomyces infections in Zimbabwe albeit there are some reports from South Africa ${ }^{104}$. Contributory factors include a low index of clinical suspicion, limited diagnostic capacity and a dearth of the requisite clinical and diagnostic expertise.

Most fungal infection studies in Zimbabwe are dated having been carried out about two decades ago ${ }^{9-11,23}$. While these indicate susceptibility in this population, they do not accurately represent the current situation in the country, especially with changes in the epidemiology of HIV whose prevalence has gone down from more than $15 \%{ }^{14}$ to about $8.7 \%$ with $85 \%$ of these receiving ART ${ }^{18}$. The health and economic challenges faced by the country with respect to public health priorities, clinical and laboratory expertise, the inadequacy of financial resources militate against the early diagnosis and treatment of fungal infections. Consequently, these health system limitations contribute to high rates of morbidity and mortality ${ }^{105}$.

As most serious fungal infections are opportunistic infections, a majority of the affected individuals are immunocompromised ${ }^{4}$. For example, cryptococcal meningitis, oesophageal candidiasis, PCP as well as aspergillosis are among the most common systemic fungal infections observed in HIV and AIDS patients, thus a combination of the underlying immunocompromised and superimposed fungal infection contributes to a higher risk of mortality ${ }^{106}$. The comorbidities necessitate the co-administration of drugs, resulting in drug-drug interactions (DDIs). In some cases, optimum therapy for fungal infections is contraindicated in conjunction with medicines used to treat co-morbid conditions in an attempt to prevent potential adverse effects and treatment failure ${ }^{107,108}$.

The preferred treatment for these fungal infections includes the administration of amphotericin B or azole antifungals such as fluconazole, itraconazole and voriconazole. All of these except voriconazole are on Zimbabwe's essential list of medicines ${ }^{109}$ and studies from other countries have suggested that renal function should be closely monitored with concomitant use of amphotericin B and tenofovir as both drugs can cause nephrotoxicity. Similarly, combination therapy of zidovudine and amphotericin B may result in anaemia and neutropenia ${ }^{108}$. Hence, as DDIs are often unavoidable in HIV-infected patients, the potential effects of these DDIs cannot be ignored $^{106}$ especially in Africa where very few drugs used have been evaluated for DDIs and pharmacogenetics ${ }^{110}$. This will potentially help in the management of patients suffering from co-morbidities as well as broaden our understanding of the effect of these DDIs in different populations. In addition to DDIs there is also a possibility of antifungal resistance ${ }^{111}$. Previous studies have reported fluconazole resistance among C. neoformans complex isolates from Africa ${ }^{112}$ and among Candida spp. isolated from women with $\mathrm{VVC}^{113}$. This has a large impact on health and well-being of affected individuals. 
Study limitations. Despite an exhaustive search in this study, we could not obtain enough local data to use for a precise estimate of the current burden, as most of the available studies were outdated. So, majority of the data used was obtained from other countries, which may introduce some inaccuracies when estimating the burden in Zimbabwe due to socioeconomic and geographical differences ${ }^{114}$. Another significant limitation is the incomplete nature of the estimates: for example, we could not estimate the burden of PCP in children or nonHIV patients, the burden of mycetoma, chromoblastomycosis as well sporotrichosis could not be estimated due to paucity of data despite reports of cases in the country. Nonetheless, our results show that fungal diseases are probably much more common than are documented in clinical practice. Our estimates provide a starting point from which to better understand the extent of the problem in the country and create awareness and propose appropriate studies and interventions to address fungal diseases that are of significant public health importance.

Recommendations. Educating the community about fungal diseases is an important step in raising awareness about the morbidity and mortality associated with these diseases. For most villages and communities across Zimbabwe, the entry point to health and health information dissemination is vested in the Community/Village Health Workers. These people are therefore integral in promoting awareness and assisting in early detection of symptoms associated with fungal diseases. Their knowledge of a community's languages and customs means that they are able to deliver health messages to groups in a culturally appropriate manner, which is also easily understood. This is an effective means of disseminating information to community members resulting in communitybased surveillance, which improves the likelihood of early case detection ${ }^{115}$, as well as reducing the stigma associated with some of the fungal diseases. The medical mycology community in Zimbabwe should therefore work closely with local organisations and community health workers to raise awareness of fungal diseases.

Schools are also a good place to promote campaigns aimed at raising awareness about fungal infections. For example, the neglected tropical disease, schistosomiasis, is a public health burden in Zimbabwe ${ }^{116}$. Educational campaigns in schools including essay competitions, drama and 'edutainment' are ways in which awareness about the disease is raised in communities. A similar approach could be used to create awareness about fungi diseases among school children.

To increase the access to better diagnostics locally, a standardised diagnostic algorithm based on clinical signs and symptoms that can be easily identified by primary healthcare professionals ${ }^{117}$ can be developed. The algorithm will help in early diagnosis and treatment of fungal diseases as well as ensure wealth of information on fungal diseases affecting the African population. This will allow interventions to be implemented in the primary healthcare setting and has the potential to significantly reduce morbidity and improve quality of life.

\section{Conclusion}

This study is the first to estimate the burden of fungal diseases in Zimbabwe and to provide an estimation of its impact on public health. The paucity of data on fungal infections in the country warrants for further epidemiology studies and better diagnostics to aid patient management.

\section{Methods}

The prevalence and incidence of fungal disease in Zimbabwe were calculated following methods previously described $^{118,119}$ and the applied formulae will be detailed below. The burden was estimated for the general healthy population and for the 'at- risk' populations including HIV/AIDS patients, survivors of pulmonary TB, cancer, chronic obstructive pulmonary disease (COPD), asthma and patients receiving critical care. National or local data were preferred, but where these were unavailable, data were extrapolated from other sources. The annual burden was estimated for each fungal disease and presented as: (i) absolute number of cases per year in the country and (ii) annual rates. The absolute cases were presented as either incidence or prevalence depending on the nature of infection. The annual rates (incidence or prevalence) were calculated using the absolute annual number of cases as the numerator and the entire Zimbabwean population as the denominator. For simplicity, the 2019 Zimbabwean population $\left(n=14,863,000^{120}\right)$ was used regardless of the year from which the numerator data originated. The United Nations population estimates 2019, WHO reports, and The Joint Nations Programme on HIV/AIDS (UNAIDS) were used for the population demographics.

Calculating fungal disease burden. Prevalence or incidence was calculated using data from published studies. Prevalence was calculated for allergic bronchopulmonary aspergillosis (ABPA), severe asthma with fungal sensitisation (SAFS), chronic pulmonary aspergillosis (CPA), recurrent vulvovaginal candidiasis (RVCC), and tinea capitis and the remaining estimates were calculated as annual incidence. Due to paucity of data, we were not able to calculate both prevalence and incidence for each disease.

Prevalence. To calculate the prevalence of ABPA, SAFS, CPA, RVCC, and tinea capitis we applied the same formulae used by GAFFI members to estimate the prevalence of fungal diseases in other countries ${ }^{55,60,121,122}$.

Annual incidence. To calculate the incidence of invasive aspergillosis, oesophageal candidiasis, candidemia and Candida peritonitis we applied the same formulae used to estimate the incidence in other countries ${ }^{55,60,121,122}$. For cryptococcal meningitis, Pneumocystis pneumonia and oral candidiasis, instead of calculating a figure based on the denominator, we doubled our at-risk population (ART naïve), being cognisant of the fact that virological failure does not always translate to immunodeficiency. 


\begin{tabular}{|l|l|}
\hline Diagnostic & Score \\
\hline PCR + laboratory + clinical + imaging & 2 \\
\hline Culture, smear, histology & 1 \\
\hline Clinical suspicion only & 0 \\
\hline Patient sample size & Score \\
\hline$\geq 10$ & 1 \\
\hline$<10$ & 0 \\
\hline Year of study & Score \\
\hline$<5$ years & 2 \\
\hline $5-10$ years & 1 \\
\hline$>10$ years & 0 \\
\hline Country (data used) & Score \\
\hline Zimbabwe & 2 \\
\hline Any other African country & 1 \\
\hline Rest of the world & 0 \\
\hline Methodology (well designed) & Score \\
\hline Yes & 1 \\
\hline No & 0 \\
\hline Type of publication & Score \\
\hline Research paper & 2 \\
\hline Case study/short reports & 1 \\
\hline Review papers & 0 \\
\hline Possible total score & $\mathbf{1 0}$ \\
\hline & \\
\hline & \\
\hline
\end{tabular}

Table 2. Scoring system for modified GRADE criteria.

\section{Cryptococcal meningitis}

$=($ Annual new AIDS cases $\times$ Proportion of AIDS patients presenting with cryptococcal meningitis $) \times 2$

\section{Pneumocystis pneumonia \\ $=($ Annual new AIDS cases $\times$ Proportion of AIDS patients presenting with Pneumocystis pneumonia $) \times 2$}

Oral candidiasis $=($ Annual new AIDS cases $\times 0.9) \times 2$

The values above and the assumptions made to obtain the accurate denominators were obtained from a systematic literature search detailed below. The assessment of the quality of the source data, country profile and assumptions made for the analyses are detailed below.

Data sources and search terms. Published papers were identified from four databases: PubMed, Web of Science, EMBASE and Google Scholar. The following search terms were used: fungal infection, fungal burden, fungal epidemiology, Zimbabwe, Southern Africa, and Africa. A second search included the same searches using the following diseases: Cryptococcus/cryptococcal, Candida/thrush, Aspergillus/aspergillosis, histoplasmosis, asthma, leukaemia, chronic obstructive pulmonary disease (COPD), Pneumocystis pneumonia/Pneumocystis jirovecii pneumonia (PJP)/Pneumocystis carinii pneumonia, chronic pulmonary aspergillosis (CPA), aspergilloma, allergic bronchopulmonary aspergillosis (ABPA), severe asthma with fungal sensitisation (SAFS), tinea/ ringworm. We used HIV data to estimate the burdens of cryptococcal meningitis (CM), candidiasis and Pneumocystis jirovecii pneumonia (PCP). Asthma, chronic obstructive pulmonary disease and tuberculosis data were used to estimate the presumed burden of allergic bronchopulmonary aspergillosis (ABPA) and chronic pulmonary aspergillosis (CPA). Burdens of candidaemia and Candida peritonitis were derived from critical care and/ or cancer patients' data.

Papers presenting incidence or prevalence of any fungal disease were evaluated using an adapted Grading of Recommendations, Assessment, Development and Evaluations (GRADE) score ${ }^{123}$ based on the following features: diagnostic accuracy, study size (using a cut-off of $>10$ cases), year of study, with more recent studies scoring higher, type of publication, with original research article scoring more, methodology and country, with studies from Zimbabwe scoring higher (Table 2). Those with an adapted GRADE mean score of $>2$ were deemed acceptable and enabled a minimum estimation of the country burden of fungal diseases (Table 3). Papers with a mean score $<2$ were excluded in the estimation of the country's burden of fungal diseases but were discussed in the review. 


\begin{tabular}{|c|c|c|c|c|c|c|c|c|}
\hline Disease & $\begin{array}{l}\text { Diagnostic } \\
\text { accuracy }\end{array}$ & $\begin{array}{l}\text { Patient sample } \\
\text { size } n>10\end{array}$ & Up to date & $\begin{array}{l}\text { Type of } \\
\text { publication }\end{array}$ & Methodology & Country & Overall score & References \\
\hline PCP & 2 & 1 & 1 & 2 & 1 & 1 & 8 & 24 \\
\hline Histoplasmosis & 1 & 1 & 1 & 1 & 0 & 2 & 6 & 10 \\
\hline \multirow{4}{*}{$\begin{array}{l}\text { Invasive asper- } \\
\text { gillosis }\end{array}$} & 2 & 1 & 1 & 2 & 1 & 0 & 6 & 124 \\
\hline & 1 & 1 & 0 & 1 & 1 & 0 & 4 & 125 \\
\hline & 1 & 1 & 1 & 1 & 1 & 0 & 5 & 126 \\
\hline & 0 & 1 & 1 & 1 & 1 & 0 & 4 & 127 \\
\hline Candidaemia & - & - & 1 & 0 & 1 & - & 2 & 128 \\
\hline $\begin{array}{l}\text { Candida } \\
\text { peritonitis }\end{array}$ & 1 & 1 & 1 & 1 & 1 & 0 & 5 & 129 \\
\hline ABPA & - & - & 1 & 0 & 1 & - & 2 & 130 \\
\hline SAFS & - & - & 1 & 0 & 1 & - & 2 & 89 \\
\hline $\mathrm{CM}$ & - & - & 2 & 0 & 1 & - & 3 & 131 \\
\hline RVVC & - & - & 2 & 0 & 1 & 0 & 3 & 132 \\
\hline Tinea capitis & 1 & 1 & 0 & 2 & 1 & 2 & 7 & 9 \\
\hline Mucormycosis & 0 & 1 & 1 & 1 & 1 & 0 & 4 & 133 \\
\hline Fungal keratitis & - & - & 1 & 0 & 1 & - & 2 & \begin{tabular}{|l|}
34 \\
\end{tabular} \\
\hline
\end{tabular}

Table 3. Modified GRADE score for the papers used for estimating burden of fungal diseases in Zimbabwe. $C M$ Cryptococcal meningitis, $P C P$ Pneumocystis pneumonia, $C P A$ chronic pulmonary aspergillosis, $A B P A$ allergic bronchopulmonary aspergillosis, $S A F S$ severe asthma with fungal sensitisation, $I A$ invasive candidiasis, $R V V C$ recurrent vulvovaginal candidiasis.

\begin{tabular}{|c|c|c|c|}
\hline & & Patient numbers and rates & Source \\
\hline \multirow{4}{*}{ Demographics } & Total population & $14,863,000$ & \multirow{4}{*}{120} \\
\hline & Children $(<15$ years $)$, & $6,230,000$ & \\
\hline & Total number of adults, & $8,633,000$ & \\
\hline & Adult women & $4,489,160$ & \\
\hline \multirow{7}{*}{ HIV/AIDS } & Current total HIV/AIDS & $1,400,000$ & \multirow{4}{*}{18} \\
\hline & Children with HIV & 84,000 & \\
\hline & Proportion of diagnosed cases on ARVs & $85 \%$ & \\
\hline & Number of diagnosed cases receiving ARVs & $1,100,000$ & \\
\hline & $\begin{array}{l}\text { Proportion of those on ARVs who fail or have ARV resistance } \\
\text { Number of diagnosed cases not receiving ARVs }\end{array}$ & \begin{tabular}{|l|}
$11 \%$ \\
300,000 \\
\end{tabular} & 135 \\
\hline & Annual new AIDS cases (at risk of OIs) & 42,857 & \\
\hline & AIDS-related deaths & 20,000 & \\
\hline \multirow{3}{*}{ Respiratory diseases } & Pulmonary tuberculosis annual incidence (survivors) & 20,430 & \multirow{3}{*}{$\begin{array}{l}80 \\
28 \\
136 \\
137,138\end{array}$} \\
\hline & Prevalence of asthma in adults & $6.9 \%$ & \\
\hline & $\begin{array}{l}\text { COPD prevalence (all GOLD stages) } \\
\text { COPD hospital admissions }\end{array}$ & \begin{tabular}{|l|}
$7.8 \%$ \\
121,728
\end{tabular} & \\
\hline Lung cancer & & 744 & 134 \\
\hline Diabetes & & $4.6 \%$ & 139 \\
\hline Leukaemia & AML & 230 & 140 \\
\hline
\end{tabular}

Table 4. Country's profile. Populations and rates required to calculate burden fungal-related diseases in Zimbabwe. COPD chronic obstructive pulmonary disease, GOLD Global initiative for Obstructive Lung Disease, $A R V$ antiretroviral, $O I$ opportunistic infection, $A M L$ acute myeloid leukaemia.

Country profile. Zimbabwe is a landlocked country situated in Southern Africa, between the Zambezi and Limpopo Rivers, bordered by Botswana, Mozambique, South Africa and Zambia. In 2019, the Zimbabwean population was projected to be 14.9 million, with $58 \%$ adults ${ }^{120}$. The number of people living with HIV/AIDS (PLWH) as of 2019 was estimated to be 1.3 million. The population estimates and HIV-related deaths were obtained from World Population Prospects and UNAIDS respectively and are shown in Table $4^{18,120}$. National TB data were obtained from the World Health Organization $(\mathrm{WHO})^{80}$. National prevalence data for lung cancer, chronic obstructive pulmonary disease (COPD), diabetes and incidence data for acute myeloid leukemia (AML) were obtained from the 2016 Global Burden of Disease study ${ }^{134}$. To estimate the burden for HIV-related fungal diseases, we have assumed a 7 -year linear decline in CD4 count to $<200 \times 10^{6} / 1$, of those not on ART, doubled to reflect those on ART who fail with ARV resistance or default (at risk of opportunistic infections). 


\begin{tabular}{|c|c|c|c|}
\hline Fungal disease & Underlying condition & Assumptions made & References \\
\hline Cryptococcal meningitis & HIV/AIDS & Assumes $7.1 \%$ of AIDS patients & 131 \\
\hline Pneumocystis pneumonia & HIV/AIDS & $\begin{array}{l}\text { Assumes } 11 \% \text { PCP as newly diagnosed HIV/AIDS adults over } \\
2 \text { years }\end{array}$ & 24 \\
\hline Invasive aspergillosis & HIV/AIDS; COPD; Leukaemia; lung cancer & $\begin{array}{l}\text { Assumes } 10 \% \text { of AML patients develop IA. Rate in non-AML same } \\
\text { as in AML. } 1.3 \% \text { of admitted COPD patients, } 2.6 \% \text { of lung cancer } \\
\text { patients and } 4 \% \text { of HIV/AIDS deaths }\end{array}$ & $124-127$ \\
\hline Chronic pulmonary aspergillosis & Tuberculosis, COPD & $\begin{array}{l}\text { Assumed that } 22 \% \text { of those with and } 2 \% \text { of those without cavities } \\
\text { after TB develop CPA; that pulmonary tuberculosis is the underly- } \\
\text { ing diagnosis in } 67 \% \text { of all CPA cases }\end{array}$ & 141 \\
\hline Allergic bronchopulmonary aspergillosis & Asthma & Assumed to occur in $2.5 \%$ of adult asthmatics & $28,130,143$ \\
\hline Severe asthma with fungal sensitisation & Severe asthma & Assumes $33 \%$ of worst $10 \%$ of adult asthmatics & 89 \\
\hline Candidemia & & $\begin{array}{l}5 / 100,000 \text { (mean of } 2-11 / 100,000) \text { with } 30 \% \text { in ICU (critical care } \\
\text { and post-surgical patients) and } 70 \% \text { in cancer and other immuno- } \\
\text { compromised patients }\end{array}$ & 128 \\
\hline Candida peritonitis & Pancreatitis, major abdominal surgery & $\begin{array}{l}\text { Assumes } 1 \text { patient with hospital-acquired (almost all post-opera- } \\
\text { tive) Candida peritonitis for every } 2 \text { patients with candidaemia, in } \\
\text { ICU }\end{array}$ & 129 \\
\hline Oral candidiasis & HIV/AIDS & Assumes it occurs in $90 \%$ of untreated HIV patients, over 2 years & 144 \\
\hline Oesophageal candidiasis & HIV/AIDS & $20 \%$ of patients not on ARVs, and $0.5 \%$ of those on ARVs & 145,146 \\
\hline Recurrent Vulvovaginal Candidiasis ( $\geq 4 \mathrm{x} /$ year) & & $6 \%$ of adult women & 132 \\
\hline Mucormycosis & & $\begin{array}{l}\text { Assumes that it affects } 2 \text { per million of the population based on data } \\
\text { from Europe }\end{array}$ & 133 \\
\hline Histoplasmosis & HIV/AIDS & Based on literature & 10 \\
\hline Tinea capitis & & Assumes $29 \%$, based on a study by Robertson and Wright (1990) & 9 \\
\hline
\end{tabular}

Table 5. Assumptions on which estimates of fungal diseases were made. COPD chronic obstructive pulmonary disease, CPA chronic pulmonary aspergillosis.

Assumptions from other published reports were used to identify the most accurate denominators to use for our estimates and these are summarised in Table 5. In brief, PCP frequency was estimated by assuming $11 \%$ of newly diagnosed HIV/AIDS adults with the risk spread over 2 years ${ }^{24}$. The prevalence of AIDS patients presenting with cryptococcal meningitis was assumed to be $7.1 \%$ based on a study by Rajasingham et al. ${ }^{131}$ among antiretroviral therapy (ART)-naive HIV patients. Chronic pulmonary aspergillosis (CPA) prevalence was estimated using the previously described approach taken by Denning et al. ${ }^{141}$, where the number of annual PTB cases with cavities (22\%) was multiplied by the incidence of CPA in cavities (22\%) and the number of PTB cases without cavities (78\%) was multiplied by CPA incidence (2\%). An estimation of a 5 -year prevalence of CPA was made, assuming a $15 \%$ annual mortality or surgical cure rate ${ }^{130}$. To calculate all cases of CPA, PTB was assumed to be the underlying disorder in $67 \%$ of cases $^{142}$. Invasive aspergillosis was estimated in haematological and lung malignancies, HIV/AIDS and COPD. It was assumed that $10 \%$ of acute myeloid leukemia (AML) patients develop IA and that an equal number of cases are found in non-AML haematological patients while $1.3 \%$ of admitted COPD patients ${ }^{124}, 2.6 \%$ of lung cancer patients ${ }^{127}$ and $4 \%$ HIV/AIDS patients who died develop IA ${ }^{125}$. ABPA estimation was made assuming that $2.5 \%$ of adult asthmatics have ABPA ${ }^{130,143}$ and although ABPA also occurs in cystic fibrosis, no estimate of the prevalence of this disease in Zimbabwe was attainable. The estimate of SAFS was as estimated at $33 \%$ of the most severe asthmatics $(10 \%)^{89}$.

Oral candidiasis was assumed to affect $90 \%$ of untreated HIV patients over 12 months, based on a study in Tanzania $^{144}$. Oesophageal candidiasis was assumed to affect $20 \%$ of advanced HIV disease patients and $0.5 \%$ of HIV patients on ARV treatment ${ }^{145,146}$. Mucormycosis was estimated to occur at a rate of $0.2 / 100,000$ (literature estimate $)^{25}$. Candidaemia cases were estimated assuming it occurs at a rate of 5 per 100,000 with $30 \%$ in ICU (critical care and post-surgical patients) and 70\% in cancer and other immunocompromised and hospitalised patients $^{128}$. For Candida peritonitis (intrabdominal candidiasis), we assumed that the rate was half of the ICU candidemia rate ${ }^{129}$. The estimated prevalence of RVVC was established assuming a frequency rate of $6 \%$ in adult women $^{132}$. Tinea capitis was estimated at $29 \%$ prevalence amongst schoolchildren in Zimbabwe ${ }^{9}$.

Received: 12 February 2021; Accepted: 8 June 2021

Published online: 24 June 2021

\section{References}

1. Denning, D. W. Minimizing fungal disease deaths will allow the UNAIDS target of reducing annual AIDS deaths below 500,000 by 2020 to be realized. Philos. Trans. R. Soc. B Biol. Sci. 371, 20150468 (2016).

2. Oladele, R. O. et al. Bridging the knowledge gap on mycoses in Africa: Setting up a Pan-African Mycology Working Group. Mycoses 63, 244-249. https://doi.org/10.1111/myc.13044 (2020).

3. World Health Organization. Guidelines for the diagnosis, prevention and management of cryptococcal disease. 62 (2018).

4. Brown, G. D. et al. Hidden killers: Human fungal infections. Sci. Transl. Med. 4, 165rv113. https://doi.org/10.1126/scitranslm ed.3004404 (2012).

5. Mortensen, K. L., Denning, D. W. \& Arendrup, M. C. The burden of fungal disease in Denmark. Mycoses 58(Suppl 5), 15-21. https://doi.org/10.1111/myc.12383 (2015). 
6. Rodrigues, M. L. \& Nosanchuk, J. D. Fungal diseases as neglected pathogens: A wake-up call to public health officials. PLoS Negl. Trop. Dis. 14, e0007964. https://doi.org/10.1371/journal.pntd.0007964 (2020).

7. Global Action Fund For Fungal Infections (GAFFI). https://www.gaffi.org/\%20roadmap/ (2015). Accessed 16 Mar 2020

8. World Health Organization. Mycetoma, chromoblastomycosis and other deep mycoses, https://www.who.int/neglected_diseases/ diseases/mycetoma/en/ (2020). Accessed 10 Nov 2020

9. Robertson, V. J. \& Wright, S. A survey of tinea capitis in primary school children in Harare, Zimbabwe. J. Trop. Med. Hyg. 93, 419-422 (1990).

10. Gumbo, T. et al. Clinicopathological features of cutaneous histoplasmosis in human immunodeficiency virus-infected patients in Zimbabwe. Trans. R. Soc. Trop. Med. Hyg. 95, 635-636. https://doi.org/10.1016/s0035-9203(01)90103-8 (2001).

11. Hakim, J. G. et al. Impact of HIV infection on meningitis in Harare, Zimbabwe: A prospective study of 406 predominantly adult patients. AIDS 14, 1401-1407. https://doi.org/10.1097/00002030-200007070-00013 (2000).

12. Ross, M. D. \& Gelfand, M. Deep fungal infections in Rhodesia-A 10-year survey of histological material. Part I. Cent. Afr. J. Med. 24, 208-212 (1978).

13. Ross, M. D. \& Gelfand, M. Deep fungal infections in Rhodesia-a 10-year survey of histological material. Part II: mycetoma pseudomycetes phycomycosis mycotic abscess favus rhinosporidiosis histoplasmosis coccidioidomycosis. Cent. Afr. J. Med. 24, 231-236 (1978).

14. Todd, C., Ray, S., Madzimbamuto, F. \& Sanders, D. What is the way forward for health in Zimbabwe?. Lancet 375, 606-609. https://doi.org/10.1016/S0140-6736(09)61498-7 (2010).

15. World Health Organization. Cholera - Zimbabwe. https://www.who.int/csr/don/05-october-2018-cholera-zimbabwe/en/ (2018). Accessed 12 July 2020

16. ProMED-mail. Typhoid fever-Zimbabwe: (HA). ProMED-mail 2018, Archive Number: 20200805.7648734. https://promedmail. org/promed-posts/ (2018). Accessed 31 July 2020

17. World Health Organization. Coronavirus disease (COVID-19) pandemic. https://www.who.int/emergencies/diseases/novel-coron avirus-2019 (2020). Accessed 20 Oct 2020

18. UNAIDS. https://www.unaids.org/en/resources/fact-sheet (2019). Accessed 21 July 2020

19. Jarvis, J. N. \& Harrison, T. S. HIV-associated cryptococcal meningitis. AIDS 21, 2119-2129. https://doi.org/10.1097/QAD.0b013 e3282a4a64d (2007).

20. Park, B. J. et al. Estimation of the current global burden of cryptococcal meningitis among persons living with HIV/AIDS. AIDS 23, 525-530 (2009).

21. Malin, A. S. et al. Pneumocystis carinii pneumonia in Zimbabwe. Lancet 346, 1258-1261. https://doi.org/10.1016/s0140-6736(95) 91862-0 (1995).

22. Limper, A. H., Adenis, A., Le, T. \& Harrison, T. S. Fungal infections in HIV/AIDS. Lancet. Infect. Dis 17, e334-e343. https://doi. org/10.1016/S1473-3099(17)30303-1 (2017).

23. McLeod, D. T. et al. Pulmonary diseases in patients infected with the human immunodeficiency virus in Zimbabwe, Central Africa. Trans. R. Soc. Trop. Med. Hyg. 83, 694-697. https://doi.org/10.1016/0035-9203(89)90400-8 (1989).

24. Taylor, S. M. et al. Low prevalence of Pneumocystis pneumonia (PCP) but high prevalence of Pneumocystis dihydropteroate synthase (dhps) gene mutations in HIV-infected persons in Uganda. PLoS ONE 7, e49991. https://doi.org/10.1371/journal.pone. 0049991 (2012).

25. Prakash, H. \& Chakrabarti, A. Global epidemiology of mucormycosis. J. Fungi 5, 26 (2019).

26. Oladele, R. O., Ayanlowo, O. O., Richardson, M. D. \& Denning, D. W. Histoplasmosis in Africa: An emerging or a neglected disease?. PLoS Negl. Trop. Dis. 12, e0006046-e0006046. https://doi.org/10.1371/journal.pntd.0006046 (2018).

27. Kosmidis, C. \& Denning, D. W. The clinical spectrum of pulmonary aspergillosis. Thorax 70, 270. https://doi.org/10.1136/thora xjnl-2014-206291 (2015).

28. Obel, K. B. et al. Prevalence and determinants of asthma in adults in Kinshasa. PLoS One 12, e0176875. https://doi.org/10.1371/ journal.pone.0176875 (2017).

29. Sobel, J. D. Vulvovaginal candidosis. Lancet 369, 1961-1971 (2007).

30. Gonçalves, B. et al. Vulvovaginal candidiasis: Epidemiology, microbiology and risk factors. Crit. Rev. Microbiol. 42, 905-927 (2016).

31. Tuli, S. S. Fungal keratitis. Clin. Ophthalmol. 5, 275-279. https://doi.org/10.2147/OPTH.S10819 (2011).

32. Ansari, Z., Miller, D. \& Galor, A. Current thoughts in fungal keratitis: Diagnosis and treatment. Curr. Fungal Infect. Rep. 7, 209-218. https://doi.org/10.1007/s12281-013-0150-110.1007/s12281-013-0150-1 (2013).

33. Deorukhkar, S., Katiyar, R. \& Saini, S. Epidemiological features and laboratory results of bacterial and fungal keratitis: A 5-year study at a rural tertiary-care hospital in western Maharashtra, India. Singap. Med. J. 53, 264-267 (2012).

34. Brown, L., Leck, A. K., Gichangi, M., Burton, M. J. \& Denning, D. W. The global incidence and diagnosis of fungal keratitis. Lancet Infect. Dis. 29, e49-e57 (2020).

35. Zaraa, I. et al. Inflammatory Tinea capitis: A 12-year study and a review of the literature. Mycoses 56, 110-116. https://doi.org/ 10.1111/j.1439-0507.2012.02219.x (2013).

36. Thakur, R. Tinea capitis in Botswana. Clin. Cosmet. Investig. Dermatol. 6, 37 (2013).

37. Simpanya, M. F. A contribution to the study of tinea capitis in Lusaka, Zambia. East Afr. Med. J. 66, 269-275 (1989).

38. Morar, N., Dlova, N. C., Gupta, A. K. \& Aboobaker, J. Tinea capitis in Kwa-Zulu Natal, South Africa. Pediatr. Dermatol. 21, 444-447 (2004).

39. Sidat, M. M., Correia, D. \& Buene, T. P. Tinea capitis among rural school children of the district of Magude, in Maputo province, Mozambique. Mycoses 49, 480-483 (2006).

40. Bongomin, F. et al. Estimation of the burden of tinea capitis among children in Africa. Mycoses https://doi.org/10.1111/myc. $13221(2020)$.

41. Baily, G. G., Robertson, V. J., Neill, P., Garrido, P. \& Levy, L. F. Blastomycosis in Africa: Clinical features, diagnosis, and treatment. Rev. Infect. Dis. 13, 1005-1008. https://doi.org/10.1093/clinids/13.5.1005 (1991).

42. Brown, E. M. et al. Phylogenetic analysis reveals a cryptic species Blastomyces gilchristii, sp. nov. within the human pathogenic fungus Blastomyces dermatitidis. PLoS One 8, e59237. https://doi.org/10.1371/journal.pone.0059237 (2013).

43. Schwartz, I. et al. Blastomycosis in Africa and the Middle East: A comprehensive review of reported cases and reanalysis of historical isolates based on molecular data. Clin. Infect. Dis. https://doi.org/10.1093/cid/ciaa1100/5885166 (2020).

44. Schwartz, I. S. et al. The estimated burden of fungal disease in South Africa. S. Afr. Med. J. 109, 885 (2019).

45. Badiane, A. S., Ndiaye, D. \& Denning, D. W. Burden of fungal infections in Senegal. Mycoses 58(Suppl 5), 63-69. https://doi. org/10.1111/myc.12381 (2015).

46. Oladele, R. O. \& Denning, D. W. Burden of serious fungal infection in Nigeria. West Afr. J. Med. 33, 107-114 (2014),

47. Sustr, V., Foessleitner, P., Kiss, H. \& Farr, A. Vulvovaginal candidosis: Current concepts, challenges and perspectives. J. Fungi 6, $267(2020)$.

48. Yano, J. et al. Current patient perspectives of vulvovaginal candidiasis: Incidence, symptoms, management and post-treatment outcomes. BMC Womens Health 19, 48-48. https://doi.org/10.1186/s12905-019-0748-8 (2019).

49. Mbizvo, E. M. et al. Association of herpes simplex virus type 2 with the human immunodeficiency virus among urban women in Zimbabwe. Int. J. STD AIDS 13, 343-348 (2002). 
50. Kurewa, N. E. et al. The burden and risk factors of sexually transmitted infections and reproductive tract infections among pregnant women in Zimbabwe. BMC Infect. Dis. 10, 127. https://doi.org/10.1186/1471-2334-10-127 (2010).

51. Sobel, J. D. Recurrent vulvovaginal candidiasis. Am. J. Obstet. Gynecol. 214, 15-21 (2016).

52. Aballéa, S. et al. Subjective health status and health-related quality of life among women with recurrent vulvovaginal candidosis (RVVC) in Europe and the USA. Health Qual. Life Outcomes 11, 169 (2013).

53. Fukazawa, E. I. et al. Influence of recurrent vulvovaginal candidiasis on quality of life issues. Arch. Gynecol. Obstet. 300, 647-650. https://doi.org/10.1007/s00404-019-05228-3 (2019).

54. Djohan, V. et al. Recurrent vulvo-vaginal candidiasis in Abidjan (Côte d'Ivoire): Aetiology and associated factors. J. Mycol. Med. 29, 127-131. https://doi.org/10.1016/j.mycmed.2019.04.002 (2019).

55. Dunaiski, C. M. \& Denning, D. W. Estimated burden of fungal infections in Namibia. J. Fungi (Basel, Switzerland) 5, 75. https:// doi.org/10.3390/jof5030075 (2019).

56. Sacarlal, J. \& Denning, D. W. Estimated burden of serious fungal infections in Mozambique. J. Fungi 4, 75 (2018).

57. Kalua, K., Zimba, B. \& Denning, D. W. Estimated burden of serious fungal infections in Malawi. J. Fungi 4, 61 (2018),

58. Borgdorff, H. et al. The association between ethnicity and vaginal microbiota composition in Amsterdam, the Netherlands. PLOS ONE 12, e0181135. https://doi.org/10.1371/journal.pone.0181135 (2017).

59. van de Wijgert, J. H. H. M. \& Jespers, V. The global health impact of vaginal dysbiosis. Res. Microbiol. 168, 859-864. https://doi. org/10.1016/j.resmic.2017.02.003 (2017).

60. Koffi, D. et al. Estimates of serious fungal infection burden in Côte d'Ivoire and country health profile. J. Med. Mycol. 31, 101086. https://doi.org/10.1016/j.mycmed.2020.101086 (2021).

61. Usluogullari, B. et al. The role of human Dectin-1 Y238X gene polymorphism in recurrent vulvovaginal candidiasis infections. Mol. Biol. Rep. 41, 6763-6768. https://doi.org/10.1007/s11033-014-3562-2 (2014).

62. Mushi, M. F. et al. Oral candidiasis among African human immunodeficiency virus-infected individuals: 10 years of systematic review and meta-analysis from sub-Saharan Africa. J. Oral Microbiol. 9, 1317579 (2017).

63. Thanyasrisung, P. et al. Oral Candida carriage and immune status in Thai human immunodeficiency virus-infected individuals. J. Med. Microbiol. 63, 753-759 (2014).

64. Akinyemi, J. O. et al. Demographic and epidemiological characteristics of HIV opportunistic infections among older adults in Nigeria. Afr. Health Sci. 17, 315-321 (2017).

65. Rubaihayo, J. et al. Frequency and distribution patterns of opportunistic infections associated with HIV/AIDS in Uganda. BMC. Res. Notes 9, 501 (2016).

66. Garcia-Cuesta, C., Sarrion-Pérez, M.-G. \& Bagán, J. V. Current treatment of oral candidiasis: A literature review. J. Clin. Exp. Dent. 6, e576-e582. https://doi.org/10.4317/jced.51798 (2014).

67. Lashof, A. O. et al. An open multicentre comparative study of the efficacy, safety and tolerance of fluconazole and itraconazole in the treatment of cancer patients with oropharyngeal candidiasis. Eur. J. Cancer 40, 1314-1319 (2004).

68. Osaigbovo, I. I., Lofor, P. V. \& Oladele, R. O. Fluconazole resistance among oral Candida isolates from people living with HIV/ AIDS in a Nigerian tertiary hospital. J. Fungi 3, 69 (2017).

69. Okonkwo, E., Alo, M., Nworie, O., Orji, J. \& Agah, M. Prevalence of oral Candida albicans infection in HIV sero-positive patients in Abakaliki. Am. J. Life Sci. 1, 72-76 (2013).

70. Njunda, L. A. et al. Oral and urinary colonization of Candida species in HIV/AIDS patients in Cameroon. Basic Sci. Med. 2, $1-8(2013)$.

71. Ambe, N. F. et al. The prevalence, risk factors and antifungal sensitivity pattern of oral candidiasis in HIV/AIDS patients in Kumba District Hospital, South West Region, Cameroon. Pan. Afr. Med. J. 36, 23-23. https://doi.org/10.11604/pamj.2020.36. $23.18202(2020)$.

72. Nweze, E. I. \& Ogbonnaya, U. L. Oral Candida isolates among HIV-infected subjects in Nigeria. J. Microbiol. Immunol. Infect. 44, 172-177 (2011).

73. Durski, K. N. et al. Cost-effective diagnostic checklists for meningitis in resource-limited settings. J. Acquir. Immune Defic. Syndr. 63, e101-108. https://doi.org/10.1097/QAI.0b013e31828e1e56 (2013).

74. Rhein, J. et al. Detrimental outcomes of unmasking cryptococcal meningitis with recent ART initiation. Open Forum Infect. Dis. 5, ofy122. https://doi.org/10.1093/ofid/ofy122 (2018).

75. Lakoh, S. et al. Prevalence and mortality of cryptococcal disease in adults with advanced HIV in an urban tertiary hospital in Sierra Leone: A prospective study. BMC Infect. Dis. 20, 141. https://doi.org/10.1186/s12879-020-4862-x (2020).

76. Mpoza, E. et al. Cryptococcal antigenemia in human immunodeficiency virus antiretroviral therapy-experienced ugandans with virologic failure. Clin. Infect. Dis. 71, 1726-1731. https://doi.org/10.1093/cid/ciz1069 (2019).

77. Ruffini, D. D. \& Madhi, S. A. The high burden of Pneumocystis carinii pneumonia in African HIV-1-infected children hospitalized for severe pneumonia. AIDS 16, 105-112. https://doi.org/10.1097/00002030-200201040-00013 (2002).

78. Morris, A. et al. Current epidemiology of Pneumocystis pneumonia. Emerg. Infect. Dis. 10, 1713-1720. https://doi.org/10.3201/ eid1010.030985 (2004).

79. Ansari, N. A. et al. Pathology and causes of death in a series of human immunodeficiency virus-positive and-negative pediatric referral hospital admissions in Botswana. Pediatr. Infect. Dis. J. 22, 43-47 (2003).

80. World Health Organization. Tuberculosis. https://www.who.int/news-room/fact-sheets/detail/tuberculosis (2018, September 18). Accessed 18 Sept 2020

81. World Health Organization. The selection and use of essential in vitro diagnostics-TRS 1031. Report No. 1031, 373 (2021).

82. Oladele, R. et al. Chronic pulmonary aspergillosis as a cause of smear-negative TB and/or TB treatment failure in Nigerians. Int. J. Tuberc. Lung Dis. 21, 1056-1061 (2017).

83. Ndarukwa, P., Chimbari, M. J. \& Sibanda, E. Assessment of levels of asthma control among adult patients with asthma at Chitungwiza Central Hospital, Zimbabwe. Allergy Asthma Clin. Immunol. 16, 10. https://doi.org/10.1186/s13223-020-0405-7 (2020).

84. Denning, D. W. et al. Randomized controlled trial of oral antifungal treatment for severe asthma with fungal sensitization: The Fungal Asthma Sensitization Trial (FAST) study. Am. J. Respir. Crit. Care Med. 179, 11-18 (2009).

85. Agarwal, R. \& Chakrabarti, A. Allergic bronchopulmonary aspergillosis in asthma: Epidemiological, clinical and therapeutic issues. Future Microbiol. 8, 1463-1474 (2013).

86. Agarwal, R. et al. Diagnostic performance of various tests and criteria employed in allergic bronchopulmonary aspergillosis: A latent class analysis. PLoS One 8, e61105 (2013).

87. Rapeport, W. G., Ito, K. \& Denning, D. W. The role of antifungals in the management of patients with severe asthma. Clin. Transl. Allergy 10, 46. https://doi.org/10.1186/s13601-020-00353-8 (2020).

88. Agarwal, R. et al. Allergic bronchopulmonary aspergillosis. Indian J. Med. Res. 151, 529-549. https://doi.org/10.4103/ijmr.IJMR_ 1187_19 (2020).

89. Denning, D. W. et al. Fungal allergy in asthma-State of the art and research needs. Clin. Transl. Allergy 4, 14 (2014).

90. Chepchirchir, A., Bii, C. \& Ndinya-Achola, J. Dermatophyte infections in primary school children in Kibera slums of Nairobi. East Afr. Med. J. 86, 59-68 (2009).

91. Emele, F. \& Oyeka, C. Tinea capitis among primary school children in Anambra state of Nigeria. Mycoses 51, 536-541 (2008).

92. Nweze, E. \& Eke, I. Dermatophytes and dermatophytosis in the eastern and southern parts of Africa. Med. Mycol. 56, 13-28 (2018). 
93. Kechia, F. A. et al. Epidemiology of Tinea capitis among school-age children in Meiganga, Cameroon. J. Mycol. Med. 24, 129-134. https://doi.org/10.1016/j.mycmed.2013.12.002 (2014).

94. Moto, J. N., Maingi, J. M. \& Nyamache, A. K. Prevalence of Tinea capitis in school going children from Mathare, informal settlement in Nairobi, Kenya. BMC. Res. Notes 8, 274. https://doi.org/10.1186/s13104-015-1240-7 (2015).

95. Emmanuel, P., Dumre, S. P., John, S., Karbwang, J. \& Hirayama, K. Mycetoma: A clinical dilemma in resource limited settings. Ann. Clin. Microbiol. Antimicrob. 17, 35-35. https://doi.org/10.1186/s12941-018-0287-4 (2018).

96. Abbas, M. et al. The disabling consequences of Mycetoma. PLoS Negl. Trop. Dis. 12, e0007019 (2018).

97. Bakhiet, S. M. et al. A holistic approach to the mycetoma management. PLoS Negl. Trop. Dis. 12, e0006391-e0006391. https:// doi.org/10.1371/journal.pntd.0006391 (2018).

98. Ndiaye, B., Develoux, M., Langlade, M. \& Kane, A. in Annales de Dermatologie et de Venereologie. 161-165.

99. Dieng, M., Niang, S., Diop, B. \& Ndiaye, B. Actinomycétomes au Sénégal. Étude de 90 cas. Bull. Soc. Pathol. Exot. 98, 14-17 (2005).

100. Dieng, M., Sy, M., Diop, B., Niang, S. \& Ndiaye, B. in Annales de Dermatologie et de Venereologie. 16-19.

101. Develoux, M., Vetter, J., Audoin, J. \& Treguer, J. 63 cases of mycetoma in the Niger Republic (etiological study based on histopathology). Bulletin de la Societe de Pathologie Exotique et de ses Filiales 78, 574-584 (1985).

102. Destombes, P., Mariat, F., Rosati, L. \& Segretain, G. Mycetoma in Somalia-results of a survey done from 1959 to 1964. Acta Trop. 34, 355-373 (1977).

103. Ahmed, A. O. et al. Mycetoma caused by Madurella mycetomatis: A neglected infectious burden. Lancet. Infect. Dis 4, 566-574 (2004).

104. Ashraf, N. et al. Re-drawing the maps for endemic mycoses. Mycopathologia https://doi.org/10.1007/s11046-020-00431-2 (2020).

105. Hayes, G. E. \& Denning, D. W. Frequency, diagnosis and management of fungal respiratory infections. Curr. Opin. Pulm. Med. 19, 259-265. https://doi.org/10.1097/MCP.0b013e32835flad1 (2013).

106. Journal, T. P. https://www.pharmaceutical-journal.com/news-and-analysis/opinion/correspondence/pharmacists-should-makethemselves-familiar-with-the-antifungal-drug-interactions-database/20208143 (2020).

107. Tseng, A. \& Foisy, M. Important drug-drug interactions in HIV-infected persons on antiretroviral therapy: An update on new interactions between HIV and non-HIV drugs. Curr. Infect. Dis. Rep. 14, 67-82. https://doi.org/10.1007/s11908-011-0229-1 (2012).

108. Vadlapatla, R. K., Patel, M., Paturi, D. K., Pal, D. \& Mitra, A. K. Clinically relevant drug-drug interactions between antiretrovirals and antifungals. Expert Opin. Drug Metab. Toxicol. 10, 561-580. https://doi.org/10.1517/17425255.2014.883379 (2014).

109. Ministry of Health and Family Welfare. Vol. 5 (The National Drug and Therapeutics Policy Advisory Committe (NDTPAC), Ministry of Health and Child Welfare, Republic of Zimbabwe, 2006).

110. Osakunor, D. N. M., Sengeh, D. M. \& Mutapi, F. Universal health coverage in africa: Coinfections and comorbidities. Trends Parasitol. 34, 813-817 (2018).

111. Africa, C. W. J. \& Abrantes, P. M. D. S. Candida antifungal drug resistance in sub-Saharan African populations: A systematic review. F1000Research 5, 2832-2832. https://doi.org/10.12688/f1000research.10327.2 (2016).

112. Bii, C. C. et al. Antifungal drug susceptibility of Cryptococcus neoformans from clinical sources in Nairobi, Kenya. Mycoses 50, 25-30 (2007).

113. Wang, F.-J., Dai Zhang, Z.-H.L., Wu, W.-X., Bai, H.-H. \& Dong, H.-Y. Species distribution and in vitro antifungal susceptibility of vulvovaginal Candida isolates in China. Chin. Med. J. 129, 1161 (2016).

114. Özenci, V. et al. Estimated burden of fungal infections in Sweden. Mycoses 62, 1043-1048. https://doi.org/10.1111/myc.12981 (2019).

115. Corley, A. G., Thornton, C. P. \& Glass, N. E. The role of nurses and community health workers in confronting neglected tropical diseases in Sub-Saharan Africa: A systematic review. PLoS Negl. Trop. Dis. 10, e0004914. https://doi.org/10.1371/journal.pntd. 0004914 (2016).

116. Midzi, N. et al. Distribution of schistosomiasis and soil transmitted helminthiasis in Zimbabwe: Towards a national plan of action for control and elimination. PLoS Negl. Trop. Dis. 8, e3014. https://doi.org/10.1371/journal.pntd.0003014 (2014).

117. Deribe, K. et al. Developing and validating a clinical algorithm for the diagnosis of podoconiosis. Trans. R. Soc. Trop. Med. Hyg. 114, 916-925. https://doi.org/10.1093/trstmh/traa074 (2020).

118. Infections, G. A. F. F. F. Publications. https://www.gaffi.org/media/academic-papers/ (2020). Accessed 13 Sept 2020

119. Sabino, R. et al. Serious fungal infections in Portugal. Eur. J. Clin. Microbiol. Infect. Dis. 36, 1345-1352. https://doi.org/10.1007/ s10096-017-2930-y (2017).

120. Nations, U. World Population Prospects. https://population.un.org/wpp/ (2019). Accessed 21 July 2020

121. Education, L. I. F. Fungal Infections. <http://www.life-worldwide.org/fungal-diseases (2020). Accessed 20 Sept 2020

122. Ocansey, B. K. et al. Estimated burden of serious fungal infections in Ghana. J. Fungi (Basel, Switzerland) 5, 38. https://doi.org/ 10.3390/jof5020038 (2019).

123. Guyatt, G. H. et al. What is "quality of evidence" and why is it important to clinicians?. BMJ 336, 995-998. https://doi.org/10. 1136/bmj.39490.551019.be (2008).

124. Lortholary, O. et al. Epidemiological trends in invasive aspergillosis in France: The SAIF network (2005-2007). Clin. Microbiol. Infect. 17, 1882-1889 (2011).

125. Antinori, S. et al. Trends in the postmortem diagnosis of opportunistic invasive fungal infections in patients with AIDS: A retrospective study of 1,630 autopsies performed between 1984 and 2002. Am. J. Clin. Pathol. 132, 221-227 (2009).

126. Guinea, J. et al. Pulmonary aspergillosis in patients with chronic obstructive pulmonary disease: incidence, risk factors, and outcome. Clin. Microbiol. Infect. 16, 870-877 (2010).

127. Yan, X. et al. Clinical characteristics of 45 patients with invasive pulmonary aspergillosis: Retrospective analysis of 1711 lung cancer cases. Cancer Interdiscip. Int. J. Am. Cancer Soc. 115, 5018-5025 (2009).

128. Arendrup, M. C. Epidemiology of invasive candidiasis. Curr. Opin. Crit. Care 16, 445-452 (2010).

129. Montravers, P. et al. A multicentre study of antifungal strategies and outcome of Candida spp. peritonitis in intensive-care units. Clin. Microbiol. Infect. 17, 1061-1067 (2011).

130. Denning, D. W., Pleuvry, A. \& Cole, D. C. Global burden of allergic bronchopulmonary aspergillosis with asthma and its complication chronic pulmonary aspergillosis in adults. Med. Mycol. 51, 361-370 (2013).

131. Rajasingham, R. et al. Global burden of disease of HIV-associated cryptococcal meningitis: An updated analysis. Lancet. Infect. Dis 17, 873-881 (2017).

132. Denning, D. W., Kneale, M., Sobel, J. D. \& Rautemaa-Richardson, R. Global burden of recurrent vulvovaginal candidiasis: A systematic review. Lancet. Infect. Dis 18, e339-e347. https://doi.org/10.1016/S1473-3099(18)30103-8 (2018).

133. Bitar, D. et al. Increasing incidence of zygomycosis (mucormycosis), France, 1997-2006. Emerg. Infect. Dis. 15, 1395-1401. https://doi.org/10.3201/eid1509.090334 (2009).

134. Evaluation, I. f. H. M. a. GBD Compare|IHME Viz Hub, https://vizhub.healthdata.org/gbd-compare/ (2017). Accessed 31 July 2020

135. Ssemwanga, D. et al. Update on HIV-1 acquired and transmitted drug resistance in Africa. AIDS Rev. 17, 3-20 (2015).

136. Musafiri, S. et al. Prevalence of atopy, asthma and COPD in an urban and a rural area of an African country. Respir. Med. 105, 1596-1605. https://doi.org/10.1016/j.rmed.2011.06.013 (2011). 
137. Hammond, E. E., McDonald, C. S., Vestbo, J. \& Denning, D. W. The global impact of Aspergillus infection on COPD. BMC Pulm. Med. 20, 1-10 (2020).

138. van Gemert, F. et al. Prevalence of chronic obstructive pulmonary disease and associated risk factors in Uganda (FRESH AIR Uganda): A prospective cross-sectional observational study. Lancet Glob. Health 3, e44-e51 (2015).

139. World Health Organization. Diabetes country profiles. https://www.who.int/diabetes/country-profiles/zwe_en.pdf?ua=1 (2016). Accessed 10 Oct 2020

140. Observatory, G. C. Zimbabwe. https://gco.iarc.fr/ (2018). Accessed 16 Mar 2020

141. Denning, D. W., Pleuvry, A. \& Cole, D. C. Global burden of chronic pulmonary aspergillosis as a sequel to pulmonary tuberculosis. Bull. World Health Organ. 89, 864-872 (2011).

142. Smith, N. \& Denning, D. Underlying conditions in chronic pulmonary aspergillosis including simple aspergilloma. Eur. Respir. J. 37, 865-872 (2011).

143. Benatar, S., Keen, G. \& Naude, W. D. T. Aspergillus hypersensitivity in asthmatics in Cape Town. Clin. Exp. Allergy 10, 285-291 (1980).

144. Matee, M., Scheutz, F. \& Moshy, J. Occurrence of oral lesions in relation to clinical and immunological status among HIV-infected adult Tanzanians. Oral Dis. 6, 106-111 (2000).

145. Smith, E. \& Orholm, M. Trends and patterns of opportunistic diseases in Danish AIDS patients 1980-1990. Scand. J. Infect. Dis. 22, 665-672 (1990).

146. Buchacz, K. et al. AIDS-defining opportunistic illnesses in US patients, 1994-2007: A cohort study. AIDS 24, 1549-1559 (2010).

\section{Acknowledgements}

We thank all the members of the Parasite Immuno-epidemiology Group at the University of Edinburgh for their valuable comments in shaping this manuscript.

\section{Author contributions}

F.M. and D.W.D. conceptualized and designed the study. L.P. and D.W.D. analysed the data. L.P. and F.M. prepared the draft manuscript. S.B., E.N.S. and D.W.D. reviewed and edited the draft manuscript. All authors read and approved the final version of the manuscript.

\section{Funding}

This research was commissioned by the National Institute for Health Research (NIHR) Global Health Research programme (16/136/33) using UK aid from the UK Government. The views expressed in this publication are those of the authors and not necessarily those of NIHR or the Department of Health and Social Care. LTP, FM and ENS are supported by OAK Foundation. DWD undertook this work without external funding.

\section{Competing interests}

LTP, FM., SB. and ENS have no competing interests to declare. DWD and family hold Founder shares in F2G Ltd, a University of Manchester spin-out antifungal discovery company. He acts or has recently acted as a consultant to Pulmatrix, Pulmocide, Zambon, iCo Therapeutics, Mayne Pharma, Biosergen, Bright Angel Therapeutics, Cipla and Metis. He sits on the DSMB for a SARS CoV2 vaccine trial. In the last 3 years, he has been paid for talks on behalf of Dynamiker, Hikma, Gilead, Merck, Mylan and Pfizer. He is a longstanding member of the Infectious Disease Society of America Aspergillosis Guidelines group, the European Society for Clinical Microbiology and Infectious Diseases Aspergillosis Guidelines group.

\section{Additional information}

Correspondence and requests for materials should be addressed to L.T.P.

Reprints and permissions information is available at www.nature.com/reprints.

Publisher's note Springer Nature remains neutral with regard to jurisdictional claims in published maps and institutional affiliations.

(c) (i) Open Access This article is licensed under a Creative Commons Attribution 4.0 International By License, which permits use, sharing, adaptation, distribution and reproduction in any medium or format, as long as you give appropriate credit to the original author(s) and the source, provide a link to the Creative Commons licence, and indicate if changes were made. The images or other third party material in this article are included in the article's Creative Commons licence, unless indicated otherwise in a credit line to the material. If material is not included in the article's Creative Commons licence and your intended use is not permitted by statutory regulation or exceeds the permitted use, you will need to obtain permission directly from the copyright holder. To view a copy of this licence, visit http://creativecommons.org/licenses/by/4.0/.

(C) The Author(s) 2021 